\title{
The influence of some morphological parameters of the stem on the resistance to lodging of oat varieties and promising lines of the North-East FASC breeding
}

\author{
Olga Zhuikova*, and Galina Batalova \\ Federal Agrarian Scientific Center of the North-East, city of Kirov, 610007, Russian Federation
}

\begin{abstract}
Resistance to stem lodging depends on the year conditions. The agro-climatic factors of the north-east of the European territory of the Russian Federation are unstable in terms of precipitation and temperature. Most of all, oat lodges in wet years, which is associated with an increase in plant length. To study the main morphological characters, the linear parameters of the stem and the indices of resistance to lodging were measured. The distribution of varieties and lines by plant length allowed to analyze the stem morphological parameters for each group. The main contribution to the length of plants is made by the upper and second internodes. A smaller proportion is accounted for by the length of the lower internode. The dependence of the resistance to lodging was revealed with the panicle length. The thicknesses of the first and second internodes affected some elements of the productivity structure (panicle length, panicle mass, the mass of 1000 grains, etc.). The Galchenko index (JG) and the ratio of the stem length to the diameter of the second internode $\left(\mathrm{Lc} / \mathrm{d}_{2}\right)$ had higher values in varieties with higher resistance to lodging. Promising lines $325 \mathrm{~h} 12,200 \mathrm{~h} 15,196 \mathrm{~h} 15,175 \mathrm{~h} 15,175 \mathrm{~h} 15$ and the Sapsan variety combined stem stability and yield.
\end{abstract}

\section{Introduction}

The value and stability of the yield are the main indicators that determine the relevance of variety use in production [1]. Its level is influenced by environmental factors and morphobiological features of the crop and variety, such as resistance to lodging, which largely depends on the plant length. The shortage of grain as a result of lodging in cereals can reach $15 . . .40 \%[2,3]$. Lodging is associated with insufficient development of the mechanical tissues of the central cylinder of the stem [4] and, to a greater extent, the upper internode [5]. The use of intervariety hybridization of oat in breeding in combination with individual selection of valuable genotypes can be effective, since the signs of the macrostructure and anatomical structure of the stem are controlled polygenically [4]. The creation of lodging-

\footnotetext{
* Corresponding author: zhuikova_o@mail.ru
} 
resistant varieties that can provide high productivity and the formation of high-quality grain is one of the priority tasks of breeding, especially in areas with unstable climatic resources.

The purpose of the work was to analyze the main morphological features of the stem in varieties and lines of glumaceous oat of competitive variety trial nursery in connection with resistance to lodging, to characterize the existing assortment on the basis of resistance to lodging and to identify significant breeding indices of resistance available for use.

\section{Materials and methods}

The research was carried out in 2019-2020 at the experimental field of the FSBSI FASC of the North-East, in accordance with the Methodology of the State Variety Trial of agricultural crops [6]. The material was 36 varieties and promising lines of glumaceous oat of the competitive nursery of the FASC of the North-East, the standard is the Krechet variety.

To study the main morphological features, 20 plants of each variety and line were measured: the length of the stem $(\mathrm{cm})$, the length $(\mathrm{cm})$ and diameter $(\mathrm{mm})$ of the first and second internodes, the length of the ear-bearing internode $(\mathrm{cm})$, the length of the panicle $(\mathrm{cm})$, the mass of the grain from the panicle $(\mathrm{g})$; the mass of 1000 grains $(\mathrm{g})$. Indices and parameters of resistance to lodging were calculated according to the formulas: JG index (Galchenko index) $=\mathrm{Lc} / \mathrm{d}_{1}$, where Lc is the length of the straw, $\mathrm{d}_{1}$ is the thickness of the straw in the first internode area [7]; $1_{2} / d_{2}$, where $l_{2}$ is the length of the second internode, $d_{2}$ is the diameter of the second internode [8], $\mathrm{Lc} / \mathrm{d}_{2}-$ the ratio of the stem length to the diameter of the second internode [9]; the perspectivity index (JP) - the percentage ratio of the mass of 1000 grains to the length of the straw; the Mexican index $(\mathrm{MJ})$ - the percentage ratio of the grain mass from the main panicle to the length of the straw [10], the RuebenbauerRiegerova index $(S)[11]$ :

$$
s=\left(\frac{l_{u . i .}}{l_{1}}+\frac{l_{u . i .}}{l_{2}}\right) \cdot \frac{d^{2}}{L c} \cdot 10,
$$

where $1_{\text {u.i }}$ is the length of the upper internode $(\mathrm{cm}), 1_{1}$ is the length of the first internode $(\mathrm{cm}), 1_{2}$ is the length of the second internode $(\mathrm{cm}), \mathrm{d}$ is the average diameter of the two lower internodes $(\mathrm{mm}), \mathrm{Lc}$ is the length of the stem $(\mathrm{cm})$. The modified RuebenbauerRiegerova index $(\mathrm{Sm})$, considering the inflorescence of the oat grain crop, was calculated using the formula:

$$
S m=\left(\frac{l_{u . i .}+l_{m}}{l_{1}}+\frac{l_{u . i .}+l_{m}}{l_{2}}\right) \cdot \frac{d^{2}}{L c} \cdot 10,
$$

where $1_{. p}$ is the length of the panicle $(\mathrm{cm})$.

The ranking of varieties and promising lines by plant length was carried out in accordance with the "International Classification of CMEA of the genus Avena L.": very low $(64.0-74.0 \mathrm{~cm})$, low $(75.0-85.0 \mathrm{~cm})$, medium-low $(86.0-96.0 \mathrm{~cm})$, medium $(97.0-107.0$ $\mathrm{cm})$, medium-high $(108.0-118.0 \mathrm{~cm})$ and high $(119.0-125.0 \mathrm{~cm})$. Meteorological conditions are described according to the data of the Kirov Regional Center for Hydrometeorology and Environmental Monitoring. The influence of weather conditions on the development of oat plants was estimated by the hydrothermal coefficient (GTC) according to A.I. Selyaninov [12]. To process the research results, the package of breeding-oriented and biometricgenetic programs AGROS, version 2.07 and the Microsoft Excel application software package were used. 


\section{Results and Discussion}

Weather factors in the north-east of the European territory of the Russian Federation are characterized by instability in terms of precipitation and temperature. Oat seedlings in 2019 appeared in the first decade of May, when the weather changed from hot to cool with frosts. In June, the weather was unstable in terms of temperature and moisture availability $(\mathrm{HTC}=2.0)$ (Table 1). In July and August, there was a low temperature background with light moderate rains $(\mathrm{HTC}=1.2-1.7)$, periodic heavy rains with strong winds negatively affected the condition of crops. The growing season of 2020, was characterized by unstable temperature in May $(\mathrm{HTC}=4.0)$ and June $(\mathrm{HTC}=1.4)$, very hot in the first half of July $(\mathrm{HTC}=1.77)$, which led to the sterilization of some flowers and negatively affected the setting of oat seeds.

Long-term research results of Sorokina A.V. and Komarova G.N. showed that oat lodges most strongly in wet years due to an increase in plant length [13]. Similar results were obtained at the experimental field of the North-East FASC in 2019, when under conditions of low temperatures and periodic heavy rainfall, the stem lodging was somewhat more intense than in 2020. Oat plants were distinguished by a higher length, the average value according to the experiment was $97.8 \mathrm{~cm}$ with a variation of the parameter from 77 to $115.8 \mathrm{~cm}$. The variability of the parameter was insignificant $(\mathrm{V}=9.8 \%)($ Table 2$)$.

Table 1. Meteorological conditions of oat growing season.

\begin{tabular}{|c|c|c|c|c|c|c|c|c|c|c|c|}
\hline \multirow[t]{3}{*}{ Month } & \multicolumn{5}{|c|}{ Air temperature, ${ }^{\circ} \mathrm{C}$} & \multicolumn{5}{|c|}{ Precipitation, $\mathrm{mm}$} & \multirow{3}{*}{ HTC } \\
\hline & \multicolumn{3}{|c|}{ by decades } & \multirow{2}{*}{$\begin{array}{c}\text { per } \\
\text { month }\end{array}$} & \multirow{2}{*}{$\begin{array}{c}+/- \text { to } \\
\text { norma } \\
1\end{array}$} & \multicolumn{3}{|c|}{ by decades } & \multirow{2}{*}{$\begin{array}{c}\text { per } \\
\text { month }\end{array}$} & \multirow{2}{*}{$\begin{array}{l}\% \text { to } \\
\text { nor } \\
\text { mal }\end{array}$} & \\
\hline & I & II & III & & & I & II & III & & & \\
\hline \multicolumn{12}{|c|}{2019} \\
\hline May & 14.5 & 14.5 & 12.1 & 13.6 & +2.8 & 6 & 13 & 18 & 38 & 68 & 1.0 \\
\hline June & 16.5 & 14.4 & 16.5 & 15.8 & -0.6 & 67.6 & 7.1 & 19 & 93.7 & 134 & 2.0 \\
\hline July & 15.2 & 17.4 & 15.6 & 16.1 & -2.2 & 14.8 & 19.3 & 23 & 57.1 & 68 & 1.2 \\
\hline August & 12.2 & 15.1 & 13 & 13.4 & -1.8 & 18 & 27 & 17 & 63 & 88 & 1.7 \\
\hline \multicolumn{12}{|c|}{2020} \\
\hline May & 14.1 & 11 & 11.4 & 12.1 & 0.9 & 7 & 36 & 46 & 89 & 165 & 4.0 \\
\hline June & 16.6 & 16.3 & 12.9 & 15.3 & -2.4 & 11 & 7 & 23 & 40 & 57 & 1.4 \\
\hline July & 21.6 & 21.7 & 18.5 & 20.5 & 1.6 & 20 & 8 & 73 & 100 & 130 & 1.6 \\
\hline August & 16.5 & 12.3 & 16.3 & 15.1 & -0.5 & 46 & 4 & 11 & 61 & 79 & 2.1 \\
\hline
\end{tabular}

Table 2. The influence of the conditions of the year on the morphological parameters of the stem of promising glumaceous varieties and promising lines of oat of FASC N-E.

\begin{tabular}{|c|c|c|c|c|c|c|}
\hline \multirow{3}{*}{ Year } & \multicolumn{2}{|c|}{ Plant length, cm } & \multicolumn{2}{c|}{ Stem length, cm } & \multicolumn{2}{c|}{ Panicle length, cm } \\
\cline { 2 - 7 } & $\begin{array}{c}\text { average } \\
\text { for } \\
\text { experimen } \\
\mathrm{t}\end{array}$ & $\begin{array}{c}\text { Variation } \\
\text { coefficient } \\
(\mathrm{V}), \%\end{array}$ & $\begin{array}{c}\text { average } \\
\text { for } \\
\text { experimen } \\
\mathrm{t}\end{array}$ & $\begin{array}{c}\text { Variation } \\
\text { coefficient } \\
(\mathrm{V}), \%\end{array}$ & $\begin{array}{c}\text { average } \\
\text { for } \\
\text { experimen } \\
\mathrm{t}\end{array}$ & $\begin{array}{c}\text { Variation } \\
\text { coefficient } \\
(\mathrm{V}), \%\end{array}$ \\
\hline 2019 & 97.8 & 9.8 & 81.3 & 10.4 & 16.4 & 7.9 \\
\hline 2020 & 88.3 & 7.4 & 72.3 & 8.0 & 16.0 & 6.8 \\
\hline
\end{tabular}

Resistance to lodging on average in the nursery was noted from 2 points in the Medved variety to 9 points in the Sapsan, Krechet varieties, line $325 \mathrm{~h} 12$, etc.

To a lesser extent, the lodging of plants was noted in the conditions of 2020 . The average length of the stem in the experiment was $88.3 \mathrm{~cm}(77 \ldots 108 \mathrm{~cm})$, with a slight change in the parameter $(\mathrm{V}=7.4 \%)$. Resistance to lodging on average in the nursery was 
noted from 5 points in the lines: $178 \mathrm{~h} 13,194 \mathrm{~h} 13$ to 9 points in the varieties Sapsan, Krechet and lines: 325h12, 46h14, 4h14.

Varieties and promising lines of competitive variety trial were mainly medium-low $(86 \ldots 96 \mathrm{~cm})-51 \%$ of the assortment and low $(75 \ldots 85 \mathrm{~cm})-$ up to $42 \%$. Depending on the conditions of the year, some genotypes also had different gradations for this parameter, with a significant increase in the length of plants within the variety, resistance decreased by $2 \ldots .5$ points (Medved, $4 \mathrm{~h} 15$ ) (Table 3 ). Correlation analysis showed a significant (at $\mathrm{p} \geq 0.95$ ) negative relationship between plant length and lodging resistance $(r=-0.52 \ldots-0.62$, at $\mathrm{p} \geq 0.95$ ).

A number of works have noted the dependence of the formation of the properties of plant resistance to stem lodging on the length and diameter of various internodes [14-17]. The ranking of varieties and lines by stem length allowed to analyze the morphological parameters of the stem for each group. The maximum contribution $(35 \ldots 49 \%)$ to the total length of plants in all groups is made by the upper internode $(27.4 \ldots 48.7 \mathrm{~cm})$ (Fig. 1), it has a direct correlation with the length of the plant $(\mathrm{r}=0.53 \ldots 0.86$, at $\mathrm{p} \geq 0.95)$ and the length of the panicle $(r=0.35 \ldots 0.73$, at $\mathrm{p} \geq 0.95)$. A smaller share is accounted for by the length of the lower internode (10-11\%), with parameters of $8.9 \ldots 11.2 \mathrm{~cm}$. The greatest length of the first internode was noted in medium- and medium-high samples $(8.3 \ldots 12.6 \mathrm{~cm})$, the minimum $(3.2 \mathrm{~cm})$ - in short ones.

Table 3. Change in the resistance score of some oat lines and varieties to lodging, depending on the length of the plant, 2019, 2020.

\begin{tabular}{|c|c|c|c|c|}
\hline Year & Variety, line & $\begin{array}{c}\text { Length } \\
\text { of the plants, } \\
\text { cm }\end{array}$ & $\begin{array}{c}\text { Characteristics of } \\
\text { the genotype by } \\
\text { plant length }\end{array}$ & $\begin{array}{c}\text { Lodging } \\
\text { resistance score }\end{array}$ \\
\hline 2019 & Sapsan & 93.4 & medium-low & 9 \\
\hline 2020 & & 87.8 & medium-low & 9 \\
\hline 2019 & $325 \mathrm{~h} 12$ & 91.6 & medium-low & 9 \\
\hline 2020 & & 90.4 & medium-low & 9 \\
\hline 2019 & $200 \mathrm{~h} 15$ & 80.7 & low & 9 \\
\hline 2020 & & 84.3 & low & 9 \\
\hline 2019 & Medved & 115.8 & medium-high & 2 \\
\hline 2020 & & 97.8 & medium & 7 \\
\hline 2019 & $46 \mathrm{~h} 14$ & 93.9 & medium-low & 8 \\
\hline 2020 & & 84.3 & low & 9 \\
\hline 2019 & $175 \mathrm{~h} 15$ & 89.9 & medium-low & 9 \\
\hline 2020 & & 106.0 & medium & 8 \\
\hline 2019 & $4 \mathrm{~h} 14$ & 112.9 & medium-high & 8 \\
\hline 2020 & & 88.1 & medium-low & 9 \\
\hline 2019 & $4 \mathrm{~h} 15$ & 106.7 & medium & 7 \\
\hline 2020 & & 87.2 & medium-low & 5 \\
\hline
\end{tabular}




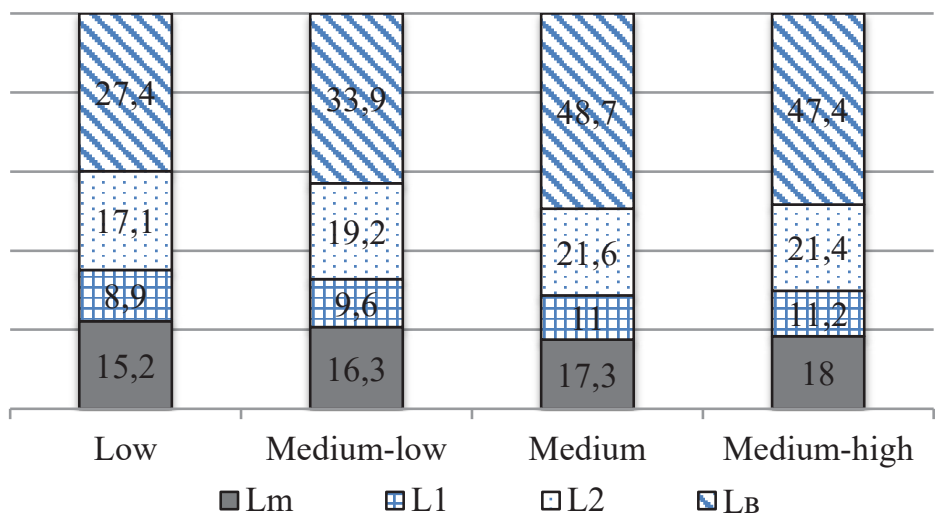

$\mathrm{Lm}$ - the length of the panicle, $\mathrm{cm} ; \mathrm{L}_{1}$ - the length of the first internode, $\mathrm{cm}$;

$\mathrm{L}_{2}$-the length of the second internode, $\mathrm{cm} ; \mathrm{Lb}$ - the length of the upper internode

Fig. 1. The contribution of the main morphological parameters of straw to the total length of plants in glumaceous varieties and lines of FASC N-E oat, 2019...2020.

In the studies of $2019 \ldots 2020$, the proportion of panicles averaged $15 \ldots 18 \%$. According to the reference data $[18,19]$, in spring oat, the proportion of panicles from the total and length of plants is from 11.5 to $25.1 \%$. In the oat genotype, the length of the panicle is related to the length of the plant [20], the higher the plant, the longer the panicle $(\mathrm{r}=0.71 \ldots 0.87$, at $\mathrm{p} \geq 0.95)$. On average, according to the experiment, the length of the panicle changed directly proportional to the length of the plant, the correlation between the length of the panicle and the resistance to lodging was inverse $(\mathrm{r}=-0.33 \ldots-0.62, \mathrm{p} \geq 0.95)$. Similar data were obtained by Gudkova G.N., Kuzenko M.V. [15].

For the thickness of the first and second internodes, an average and high correlation with the length of plants was noted $(\mathrm{r}=0.46 \ldots 0.71)$, with the length of the panicle $(0.58 \ldots 0.72)$, the mass of the panicle $(0.55 \ldots 0.81)$, the mass of grains from the panicle $(\mathrm{r}=0.37 \ldots 0.82)$, the number of grains from the panicle $(\mathrm{r}=0.45 \ldots 0.78)$ (Table 4$)$.

Table 4. Correlation coefficients of the thickness of the stem internodes with some elements of the structure of productivity and resistance to lodging

\begin{tabular}{|l|c|c|c|c|c|c|}
\hline \multirow{2}{*}{$\begin{array}{c}\text { Parameters } \\
\text { of the productivity } \\
\text { structure }\end{array}$} & \multicolumn{2}{|c|}{$\begin{array}{c}\text { Thickness of the } \\
\text { first internode }\end{array}$} & \multicolumn{2}{c|}{$\begin{array}{c}\text { The thickness of the } \\
\text { second } \\
\text { internode }\end{array}$} & \multicolumn{2}{c|}{$\begin{array}{c}\text { The thickness of the } \\
\text { upper } \\
\text { internode }\end{array}$} \\
\cline { 2 - 7 } & 2019 & 2020 & 2019 & 2020 & 2019 & 2020 \\
\hline Plant length & $0.46^{*}$ & $0.52^{*}$ & $0.49^{*}$ & $0.71^{*}$ & $0.75^{*}$ & 0.31 \\
\hline Panicle length & $0.58^{*}$ & $0.67^{*}$ & $0.72^{*}$ & $0.63^{*}$ & $0.64^{*}$ & 0.02 \\
\hline Panicle mass & $0.69^{*}$ & $0.55^{*}$ & $0.71^{*}$ & $0.81^{*}$ & $0.76^{*}$ & 0.02 \\
\hline $\begin{array}{l}\text { Grain mass in the } \\
\text { panicle }\end{array}$ & $0.68^{*}$ & $0.37^{*}$ & $0.57^{*}$ & $0.82^{*}$ & $0.78^{*}$ & $0.36^{*}$ \\
\hline Number of grains & $0.50^{*}$ & $0.51^{*}$ & $0.45^{*}$ & $0.78^{*}$ & $0.75^{*}$ & 0.05 \\
\hline Resistancetolodging & 0.02 & 0.02 & 0.30 & 0.02 & 0.01 & -0.05 \\
\hline
\end{tabular}

* - the parameter is significant at $\mathrm{p} \geq 0.95$

The effect of the thickness of stem internodes on the resistance to lodging has not been established. The correlation dependence of the thickness of the upper internode was not uniform over the years, it varied from insignificant to strong.

In addition to linear indicators, the ratio of individual stem parts was considered. Higher values of the Galchenko index $(\mathrm{JG})$, the ratio of the stem length to the diameter of the 
second internode $\left(\mathrm{Lc} / \mathrm{d}_{2}\right)$, were found in varieties and lines with higher resistance to lodging (Table 5).

Table 5. Resistance indices of varieties and lines of competitive trial of various lengths.

\begin{tabular}{|l|c|c|c|c|c|c|c|c|}
\hline \multicolumn{1}{|c|}{ Group } & $\mathrm{JG}$ & $\mathrm{Lc} / \mathrm{d}_{2}$ & $\mathrm{l}_{2} / \mathrm{d}_{2}$ & $\mathrm{~S}$ & $\mathrm{Sm}$ & $\mathrm{JP}$ & $\mathrm{MG}$ & $\begin{array}{c}\text { Average score } \\
\text { of resistance } \\
\text { to lodging }\end{array}$ \\
\hline Low & $\frac{191.3}{5.8}$ & $\frac{190.2}{7.1}$ & $\frac{48.9}{3.7}$ & $\frac{10.7}{2.2}$ & $\frac{15.6}{19.9}$ & $\frac{49.4}{12.9}$ & $\frac{2.1}{23.1}$ & 8.6 \\
\hline Medium-low & $\frac{200.0}{7.4}$ & $\frac{196.3}{9.7}$ & $\frac{48.4}{8.6}$ & $\frac{12.3}{21.3}$ & $\frac{18.0}{18.6}$ & $\frac{48.5}{12.0}$ & $\frac{2.1}{16.6}$ & 8.2 \\
\hline Medium & $\frac{214.6}{5.5}$ & $\frac{209.8}{9.8}$ & $\frac{53.8}{7.0}$ & $\frac{10.9}{12.4}$ & $\frac{15.4}{10.7}$ & $\frac{43.6}{8.6}$ & $\frac{1.99}{19.3}$ & 7.1 \\
\hline Medium-high & $\frac{223.8}{2.8}$ & $\frac{227.8}{2.5}$ & $\frac{53.8}{11.8}$ & $\frac{10.5}{17.8}$ & $\frac{14.8}{21.4}$ & $\frac{41.3}{12.9}$ & $\frac{1.9}{20.9}$ & 5.0 \\
\hline
\end{tabular}

Note: in the numerator, the index of resistance to lodging, in the denominator - the coefficient of parameter variation $(\mathrm{V}, \%)$.

These dependencies confirmed reliable correlations $(\mathrm{r}=-0.54)$ and $(\mathrm{r}=-0.44)$, respectively. For the ratio of the length of the second internode to its diameter $\left(l_{2} / \mathrm{d}_{2}\right)$, the interrelation between the first, second internode and the panicle $(\mathrm{S}, \mathrm{Sm})$ did not reveal such a dependance. At the same time, the variability of the studied indices was mainly from insignificant $(2.5 \%)$ to average $(23 \%)$.

The prospectivity index (JP) and the Mexican index (MG), which consider the yield qualities, had higher values for more resistant varieties. But the relationship of lodging with the prospectivity index $(\mathrm{r}=-0.15 \ldots-0.54)$ and the Mexican index $(\mathrm{r}=-0.04 \ldots-0.32)$ was ambiguous. Resistance to lodging ultimately affects the main variety quality - yield. The studies established a high reliable dependence of the resistance to lodging with grain yield $(\mathrm{r}=-0.63 \ldots-0.84)$.

Among the studied varieties and lines, promising ones were identified for use as sources of resistance to lodging with a stem length of $85.9 \ldots 98.2 \mathrm{~cm}$ (Table 6).

Table 6. Varieties and promising lines of oat of the competitive variety trial of the FASC of the North-East with economically valuable parameters, $2019 \ldots 2020$.

\begin{tabular}{|c|c|c|c|c|}
\hline $\begin{array}{c}\text { Varieties } \\
\text { and } \\
\text { lines }\end{array}$ & $\begin{array}{c}\text { Resistance to } \\
\text { lodging, }\end{array}$ & $\begin{array}{c}\text { Length } \\
\text { of plants }\end{array}$ & \multicolumn{2}{|c|}{ Grain yield, } \\
\cline { 2 - 5 } & score & cm & t/ha & \pm to st. \\
\hline Sapsan & $8-9$ & 90.6 & 6.4 & 0 \\
\hline $325 \mathrm{~h} 12$ & 9 & 91.0 & 7.6 & +1.2 \\
\hline $200 \mathrm{~h} 15$ & 9 & 82.5 & 6.6 & +0.2 \\
\hline $196 \mathrm{~h} 15$ & $7-8$ & 98.2 & 6.7 & +0.3 \\
\hline $175 \mathrm{~h} 15$ & $8-9$ & 98.0 & 6.4 & 0 \\
\hline $174 \mathrm{~h} 15$ & $8-9$ & 91.1 & 6.9 & +0.5 \\
\hline $\begin{array}{c}\text { Krechet- } \\
\text { standard }\end{array}$ & $7-8$ & 85.9 & 6.4 & \\
\hline
\end{tabular}

\section{Conclusion}

As a result of the study, the varieties were ranked according to plant length and resistance to lodging. Promising lines with grain yield above or at the level of the Krechet standard are 
highlighted. In the conditions of the Volga-Vyatka region of Russia, the study of morphological parameters of the stem of oat varieties and promising lines showed that the length of plants varies depending on the conditions of the year. In wetter conditions, taller plants are formed, which negatively affects the resistance to lodging. The main contribution to the plant length is made by the upper internode, but its influence on the resistance to lodging is not significant. The resistance to lodging depended, in most cases, on the length of the panicle $(\mathrm{r}=-0.33 \ldots-0.62)$. The thickness of the first and second internodes affected some elements of the productivity structure (panicle length, panicle mass, the mass of 1000 grains, etc.). In addition to the visual assessment of resistance to lodging in the field, the most identical calculations should be used, especially in years with a weak manifestation of the parameter, according to the Galchenko index, the prospectivity index, the Mexican index, the ratio of the stem length to the diameter of the second internode. Promising lines $325 \mathrm{~h} 12,200 \mathrm{~h} 15,196 \mathrm{~h} 15,175 \mathrm{~h} 15,175 \mathrm{~h} 15$ and the Sapsan variety combining stem stability and grain yield were identified.

\section{References}

1. V. Povilaitis, Soil and Plant Science, 1(68), $86 \quad$ (2018) DOI10.1080/09064710.2017.1367834

2. E.D. Nettevich, A.V. Sergeev, E.V. Lyzlov, Grain forage crops, 255 (Moscow, Rossel'hozizdat, 1980)

3. N.N. Tret'yakov, A.F. Yakovlev, Biological bases of increasing the productivity of agricultural crops, 54 (Moscow, 1984)

4. A.I. Myhlyh, S.V. Lazarevich, S.P. Haleckij, Bulletin of the Belarusian State Agricultural Academy, 2, 82 (2015)

5. A.V. Pinkal', Yu.V. Krivko, L.A. Krotova, N.G. Kazydub, Omsk scientific bulletin, 2 (114), 172 (2012)

6. Method of state variety testing of crops, 267 (Moscow: Kolos, 1985)

7. I.N. Gal'chenko, Report AN USSR, 5 (83) 749 (1952)

8. V.A. Gorshkova, Herald RAAS, 6, 25 (1992)

9. A.A. Basistov, Scientific and technical bulletin RIP, 206, 31 (1990)

10. T.G. Golova, Creation of the initial material in the selection of spring barley for nonoccurrence and productivity in the conditions of the Central Chernozem zone: abstract, dissertation, candidate of agricultural sciences, 23 (Nemchinovka, 1992)

11. L.N. Kovrigina, Herald KemSU, 2 (10), 53 (2002)

12. G.T. Selyaninov, Works on agricultural meteorology, 20, 165 (1928)

13. A.V. Sorokina, G.N. Komarova, Siberian Bulletin of Agricultural Science, 6 (241), 55 (2014)

14. S.V. Lazarevich, Herald Belarussian SAA, 3, 66 (2016)

15. G.N. Gudkova, M.V. Kuzenko, Herald ASU, 1 (196) 81 (2017)

16. L.N Kovrigina, A.V. Zaushincena, Herald KrasSAU, 157 (2010)

17. M.V. Kuzenko, V.I. Kuzenko, New technologies, 5 (16), 63 (2020) https: //doi.org/10.47370/2072-0920-2020-16-5-63-70

18. Yu.S. Ivanova, M.N. Fomina, Agric. Sci. Euro-North-East, 3 (58), 15 (2017)

19. N.A. Rodionova, V.N. Soldatov, V. E. Merezhko, Cultural flora. Oats. 2(3), 368 (Moscow: Kolos, 1994) 
20. I.G. Loskutov, Oats (Avenae L.) Distribution, systematics evolution and breeding value, 336 (SPb: SSC RF RIP 2006) 